\title{
Salience of Student Written Feedback by Peer-Revision in EFL Writing Class
}

\author{
Zhu Lei ${ }^{1}$ \\ ${ }^{1}$ School of Foreign Languages, University of Jinan, China \\ Corresponding: Zhu Lei, School of Foreign Languages, University of Jinan, Jinan, 250022, China. Tel: \\ 86-137-9100-2199. E-mail:sfl_zhul@ujn.edu.cn
}

Received: September 20, 2017 Accepted: November 6, 2017 Online Published: November 8, 2017

doi: 10.5539/elt.v10n12p151 URL: http://doi.org/10.5539/elt.v10n12p151

\begin{abstract}
The study investigates the incorporation and effectiveness of student written feedback and their attitudes towards peer feedback in writing class. Taking a qualitative case study approach, this study followes closely a class of thirty-two English juniors over one semester. Data sources include composition drafts, student written feedback and interviews. The data collected demonstrates that students generally accept peer feedback and incorporate most of their peers' comments and suggestions into their writing revision and that peer feedback provides them with more chances to discuss with their peers and understand their peers' suggestions on the composition improvement.
\end{abstract}

Keywords: feedback, peer feedback, EFL writing

\section{Introduction}

Revision is a necessary and crucial step to a successful composition of different degrees which depends on the author's writing competence and the efficacy of the instructions received (Hedgcock \& Lefkowitz, 1992:256). Feedback refers to the revision suggestions which help the author to identify and avoid errors. In EFL writing class, there are four types of feedback, namely, teacher feedback, peer evaluation, self-assess and cyber based revision, of which teacher feedback has been a traditional research focus for many years. However, with the process approach coming into writing class, peer response became a vital component in classroom teaching. Former researches expound topics as comparison between teacher feedback and peer response, feasibility and uptake of peer critiquing, and implementation of peer editing. Leki (1990) found that grammatical errors received more attention than discourse structures during peer reviewing. Mei (2010) also proved that $82.4 \%$ of peer feedback falls on surface forms. However, different ideas indicate that comment on content and structure is also remarkable in peer feedback (Berger, 1999; Miao, 2006). Though researches lead to conflicted conclusions, no doubt the effectiveness on composing is at least testified by author's awareness of readers' existence.

\section{Literary Review}

Feedback study in writing class began with the finding that it is the crucial task for writing teachers. Written feedback actually is the input from a reader to a writer which provides information to the author for revision, including comments, questions, and suggestions put forward by a reader. It is an opportunity when the writer knows about his or her problems and the reader's responses. Consequently, the writer could revise the original by adding more information, enhancing logical organization, clarifying development of ideas or correcting word-choice or tense (Keh, 1990).

In writing instruction, written feedback takes many different forms. For example, in terms of large category, there are content feedback and form feedback, which refers to the mechanics and grammar comments that provide requests or suggestions about grammatical errors and wrong word spellings (Walz, 1982; Mings, 1993; Ferris and Roberts, 2001; Ellis, 2009). Content feedback is the revision advice aiming at the content of students' writing and at the meaning of text (Connors \&Lunsford, 1993; Ferris, 1997; Hyland \& Hyland, 2001; Lin, 2009).

Peer revision, also called peer review, peer feedback, peer critiquing or peer evaluation, is a collaborative learning activity during which language learners exchange their writing drafts and give feedback to each other for the purpose of revision (Mangelsdorf, 1992). It has been applied in both the first-language (William \& Robert, 1996) and second language writing classrooms (Dana \& Hedgcock, 2005) in the past two decades. Taking 
Vygostsky's learning and language development theories as theoretical foundation, peer revision has had great influence on writing instruction in EFL context and has triggered a number of studies (Dana \& Hedgcock, 2005).

Researches into the effectiveness show that peer revision can provide students multiple sources of feedback (Mittan, 1989), increase their awareness of the reader (Zamel, 1982), build the writer's confidence (Leki, 1990), involve them into consideration of wording (Mendonca \& Johnson, 1994), and thus enjoy more opportunities to practice the second language in a meaningful context (Liu \& Hansen, 2002). However, negative views on peer revision also find their way into a number of researches, claiming that frustrating feedback may be delivered to the writer when the reader fail to express his or her comments in a proper way or on slippery ground due to the lack of experience, deficiency of professional knowledge (Mangelsdorf, 1992), doubt about their peers' ability and distrust about their feedback (Carson \& Nelson, 1996). Consequently, there are researches stating that enough training would help them to be qualified peer evaluators and competent responders (Stanley, 1992).

It is obvious that students fail to realize the significance and function of peer feedback. This situation needs to be and will be changed and improved with the rise of social-cognitive theory. Therefore, this research attempts to investigate the following questions.

(1) To what degree do students incorporate peer feedback into their writings?

(2) What are the students' attitudes towards peer feedback?

\section{Research Methodology}

\subsection{The Design}

The instrument used in this research includes two writing assignments set respectively two rounds of composition writing, questionnaire and interviews. All informants were required to finish the first drafts before the final version, each of which should at least contain 400 English words. The topics of the two assignments were selected by their English teacher who lectures the course Advanced English, which is the major course for English majors, for them. The two topics were of general interests and no expertise is needed in writing.

Interviews were conducted after finishing the writing task and peer feedback activity to further complement their views and opinions. The semi-structured interviews was designed with open-ended questions focusing on the following three topics: (1) What is the quality of peer feedback? (2)To what extent do they incorporate peer feedback? (3) What are the informants' attitudes towards peer comment?

Referring to Jacobs et al. (1998) and Zhang (1995) covering the activity of giving and receiving peer feedback, the questionnaire was piloted in another junior class of English Department. After being mended, it was delivered to the participants. The questionnaire considers the double role of the informants both as the feedback provider and receiver. It mainly includes question of three aspects: (1) the usefulness of reading peers feedback; (2) the usefulness of reading peers' writing; (3) students' acceptance of peer feedback.

Thus, data sources include, students' writing drafts, their written feedback, questionnaire and interviews.

\subsection{Subjects}

The subjects of this research are a class of thirty-two English juniors, English Department, University of Jinan. As English majors, they have finished two years of English courses, which cover language skills like listening, speaking, reading and writing. Especially, they finished three academic courses concerning writing, namely, Introduction to English Writing, English Writing and Advanced English Writing, which were lectured by foreign teacher either coming from USA or UK. Thus, they were familiar with fundamental skills and strategies of composing, and were cognitively competent to take part in peer feedback activity. No informants were informed that they were participating in the peer feedback research. This ensured that all of them were less sensitive to the writing task and behave normally in the research.

They have different future plans which influence their current willingness to compose. Among the thirty two students, one aims to take IELTS to seek a chance of pursuing master's degree in USA after graduation, two decide to participate in domestic postgraduate examinations, and the rest want to find a job when fresh from university. Table 1 demonstrates the distribution of the future plan of all the students in the School of Foreign Languages, University of Jinan. 
Table 1. Future plan distribution

\begin{tabular}{lll}
\hline Plan & Participants & All students \\
\hline Oversea study & $4(12.5 \%)$ & $16(12.8 \%)$ \\
Domestic master candidate & $12(37.5 \%)$ & $45(35.7 \%)$ \\
Employee & $16(50.0 \%)$ & $65(51.5 \%)$ \\
Total & $32(100 \%)$ & $126(100 \%)$ \\
\hline
\end{tabular}

In terms of gender, there are 103 female and 23 male students in the School of Foreign languages. The percentage of female students is about $81.7 \%$, and is quite close to that of the female participants of this research with a proportion of $83.3 \%$.

Therefore, these six students who are chosen to participate in this research can represent the students of the School and could be a reliable and meaningful source.

\subsection{Data Collection}

To get a detail investigation of students, the researcher followed the classroom instruction 15 times for about 27.5 hours. The participants finished two writing tasks and for each writing assignment, they had to accomplish the first draft and revise it according to peer response, and then handed in the final version. At the end of the semester, all the participants received an interview about 30 to 50 minutes respectively to further complement their views and perceptions. The researcher interacted with the participants in various settings like classrooms, lecture halls, offices, dormitories, and in the eateries. All their drafts were rated in holistic and analytic rubric. The interviews with the participants were audio taped by the permission of the interviewees, and later the recording was transcribed into scripts for further analysis. As for the questionnaire survey, all the thirty two participants handed back their answer sheets.

Thus, data of this research is composed of first drafts and the final drafts in two rounds of composing, peer critique sheet, questionnaires and recording transcript of interviews with the participants.

\subsection{Data Analysis}

A descriptive analysis of the writing drafts in the two rounds of composition writing was engaged. The peer feedback was above all coded into feedback points. According to Hyland (1998), each written mark concerning different aspects of writing was considered as one independent feedback point, which include underlining, symbols, comments, suggestions and rectification as well. All these points were further labeled as useless feedback or usable feedback which refers to those that can take effect to some degree in the revision. This was done respectively by two experienced English teachers, with all disagreement being discussed before the final decisions. Then, these useful peer responses which were incorporated by composition writers were graded as used feedback and those failed to be accepted as unused ones. To investigate the effectiveness of revisions, the improvement of the final version over the first drafts was also measured. The drafts and the final version of all thirty two participants were rated by two experienced raters to make sure the improvements made by the composers taking into consideration the overall the five analytic aspects including content, organization, grammar, vocabulary, and mechanism, and the three types including corrective, suggestive and complimentary. The raters were not informed about which the first and the final drafts were.

Participants' answers to the questionnaires were tabulated. Their attitudes towards peer response can be demonstrated through analysis of the survey. In addition, the interviews can further complement their understanding of peer feedback.

\section{Results and Discussion}

\subsection{Draft Revision Analysis}

Data collected from the first draft and the final version were analyzed using SPSS to investigate participants' acceptance of peer feedback. By comparing the first draft and the final writing, examination of peer's written feedback was conducted to find out whether they were incorporated in the final composition. Table 2 demonstrates the number of peer revisions suggested and those accepted. 
Table 2. Comparison between revisions made and accepted

\begin{tabular}{llcc}
\hline Aspects & & Revision Made & Peer Feedback Accepted \\
\hline Content & Idea & $57(15.4 \%)$ & $39(15.7 \%)^{*}$ \\
& & $(68.4 \%)^{* *}$ \\
& Organization & $38(10.3 \%)$ & $22(8.8 \%)^{*}$ \\
& & $(57.9 \%)^{* *}$ \\
Form & Lexical Choice & $99(26.6 \%)$ & $56(22.8 \%)^{*}$ \\
& & $(56.5 \%)^{* *}$ \\
& Grammar & $120(32.3 \%)$ & $84(33.8 \%)^{*}$ \\
& & $(70.0 \%)^{* *}$ \\
& Mechanics & $57(15.4 \%)$ & $47(18.9 \%)^{*}$ \\
& & $(82.5 \%)^{* *}$ \\
& & $248(100 \%)^{*}$ \\
& & & $(66.8 \%)^{* *}$ \\
\hline
\end{tabular}

${ }^{*}$ calculated out of 248 accepted peer feedback.

** calculated out of the numbers in Colum "Revision Made".

It is obvious that form-based feedback outnumbered content-based feedback with the percentage rate of $74.3 \%$ to $25.7 \%$. Students tend to provide far less content feedback than form feedback. There were several reasons accounting for this phenomenon. Firstly, most of the participants were not competent enough to give feedback on content, with the worry that they may misunderstand the writers' intention and thus provide unqualified suggestions. In addition, participants preferred to offer advice on grammar, wording and mechanics, which seem much easier than those on content.

It can also be found that $66.8 \%$ of the peer feedback received positive responses from the composition writers and were accepted in the revision of their writing. It reveals that participants were willing to revise their writing based on the peer feedback they had received. A very likable reason accounting for this is that it is easier for the feedback providers to give this kind of feedback and for the feedback receivers to judge the responses and revise their writing according to them. Anyway, informants do benefit form peer feedback, which helps them to realize their errors they fail to notice before and to make them consider the reception of readers.

\subsection{Questionnaire Result Analysis}

Taking into consideration the double role of the informants both as the feedback provider and receiver, the questionnaire includes 15 questions concerning the following three aspects: (1) the usefulness of reading peers feedback (question 1-5); (2) the usefulness of reading peers' writing (question 6-10); (3) students' acceptance of peer feedback (question 11-15). The choices of questions of aspect 1 and 2 are made according to Likert Scale, that is, with five choices, as "strongly agree", "agree", "neutral", "disagree", and "strongly disagree". After data being analyzed by SPSS13.0, a descriptive account was given with mean, standard deviation, and so on.

The responses of question 1 to 5 show that majority of the informants maintain that reading peer feedback is helpful with $62.3 \%$ agree and $12.1 \%$ strongly agree. Most of the participants $(71.3 \%)$ reveal that it is effective to improve their writing both in form (57.9\% agree) and content (51.2\% agree). It indicates participants' positive attitude towards the effectiveness of peer feedback.

Question 6 to 10 focus on the usefulness of reading peers' writing. The result is shown in Table 3. 
Table 3. Responses about reading peers' writing

\begin{tabular}{|c|c|c|c|c|c|}
\hline Questions & $\begin{array}{l}\text { Strongly } \\
\text { disagree }\end{array}$ & Disagree & neutral & agree & $\begin{array}{l}\text { Strongly } \\
\text { agree }\end{array}$ \\
\hline $\begin{array}{l}\text { 6. Reading other's composition gives me more } \\
\text { ideas. }\end{array}$ & 0 & $\begin{array}{l}2 \\
(6.2 \%)\end{array}$ & $\begin{array}{l}10 \\
(31.3 \%)\end{array}$ & $\begin{array}{l}17 \\
(53.1 \%)\end{array}$ & $\begin{array}{l}3 \\
(9.4 \%)\end{array}$ \\
\hline $\begin{array}{l}\text { 7. Reading other's composition helps me pay } \\
\text { attention to organization. }\end{array}$ & $\begin{array}{l}1 \\
(3.1 \%)\end{array}$ & $\begin{array}{l}4 \\
(12.5 \%)\end{array}$ & $\begin{array}{l}12 \\
(37.5 \%)\end{array}$ & $\begin{array}{l}15 \\
(46.9 \%)\end{array}$ & 0 \\
\hline $\begin{array}{l}\text { 8. Reading other's composition helps me pay } \\
\text { attention to grammar. }\end{array}$ & 0 & $\begin{array}{l}5 \\
(15.6 \%)\end{array}$ & $\begin{array}{l}7 \\
(21.9 \%)\end{array}$ & $\begin{array}{l}19 \\
(59.4 \%)\end{array}$ & $\begin{array}{l}1 \\
(3.1 \%)\end{array}$ \\
\hline $\begin{array}{l}\text { 9. Reading other's composition helps me pay } \\
\text { attention to wording. }\end{array}$ & 0 & $\begin{array}{l}5 \\
(15.6 \%)\end{array}$ & $\begin{array}{l}5 \\
(15.6 \%)\end{array}$ & $\begin{array}{l}20 \\
(62.6 \%)\end{array}$ & $\begin{array}{l}2 \\
(6.2 \%)\end{array}$ \\
\hline $\begin{array}{l}\text { 10. Reading other's composition helps me pay } \\
\text { attention to mechanics. }\end{array}$ & 0 & $\begin{array}{l}1 \\
(3.1 \%)\end{array}$ & $\begin{array}{l}5 \\
(15.6 \%)\end{array}$ & $\begin{array}{l}24 \\
(75.1 \%)\end{array}$ & $\begin{array}{l}2 \\
(6.2 \%)\end{array}$ \\
\hline
\end{tabular}

Table 3 demonstrates the high percentage of the participants who thought positively about reading their classmates' composition. They believe that it do help them in the five aspects as idea, organization, grammar, lexicon, and mechanics.

The uptake of peer feedback is shown in participants' responses to question 11 to 15 . For this part, a five Likert scale with 1 for "never" and 5 for "always" is adopted. Therefore, the mean score that is lower than 3 indicates a negative attitude and that is higher than 3 implies a positive one. Table 4 demonstrates the statistics of the participants' uptake of peer feedback.

Table 4. Acceptance of peer feedback

\begin{tabular}{llllll}
\hline & $\mathrm{N}$ & Minimum & Maximum & Mean & Std. Deviation \\
\hline Q11 & 32 & 2.00 & 5.00 & 3.4976 & .67347 \\
Q12 & 32 & 1.00 & 4.00 & 3.2375 & .79993 \\
Q13 & 32 & 1.00 & 4.00 & 3.1241 & .89794 \\
Q14 & 32 & 2.00 & 5.00 & 3.6758 & .60221 \\
Q15 & 32 & 2.00 & 5.00 & 3.4796 & .96052 \\
\hline
\end{tabular}

As is shown in this table, the overall mean score of this part is 3.42 , higher than the midpoint 3 , which indicates that participants' positive attitude. Thus, it is safe to say that informants tend to be willing to incorporate peer feedback in the revision of their compositions.

\subsection{Interview Result Analysis}

The semi-structured interviews was carried out after the questionnaire in order to supplement the quantitative analysis. The six interviewees were randomly selected from the thirty two students to do the interview in which the core questions focused on the following three topics: (1) What is the quality of peer feedback? (2)To what extent do you incorporate peer feedback? (3) Do you like peer feedback?

The very first question in the interview aimed at finding out information about the quality of peer feedback. One of the informants claimed that he preferred peer feedback because he found quite a number of interesting ideas and useful suggestions. However, he also admitted that he himself was not confident enough to give feedback to others. This view was echoed in the answers of other three interviewees. One of them said that she was gratitful towards peer feedback which correct her careless mistakes, provide constructive advice and strengthen her confidence by giving a lot of praises. Of course, there are some different voices which indicate their preference of teacher feedback than peer feedback. They believe that teachers are more authoritative and can provide high quality comments.

The second question was designed to investigate students' incorporation of peer feedback. All of the 
interviewees stated their willingness to consider peer comments on grammar and mechanics, with one saying that the specific suggestions helped him a lot in revision of his writing. However, they were reluctant to accept those responses concerning content and organization. One of them confessed, "Though I was advised to rearrange my first two paragraphs, I remained the original organization because I thought mine seemed reasonable."

The last question also received positive responses from the interviewees. Almost all of them expressed their preference for peer feedback. One of them reported that when they were exchanging, he knew more ideas and when they were discussing with each other, he understood the topic more profoundly. Some others mentioned that they did want to receive teacher feedback but they were not against peer critiquing.

\section{Conclusion}

With the above analysis and discussion, the major findings were summarized in reply to each question.

Research question 1: To what degree do students incorporate peer feedback into their writings?

Generally, students incorporate most of the peer feedback into their writings after receiving them. According to the number of peer feedback received and incorporated in the final draft, $64.2 \%$ content-based feedback and $67.8 \%$ form-based feedback were accepted by the original writers, which indicates the effectiveness of peer feedback on composition revision. It can also be found that more feedback is given to form rather than to content Consequently, more revisions on form are made than those on content, which reveals that students are less capable of giving content comments than giving form critiques. It is shown that peer feedback is effective for students to improve their composition on all the five writing dimensions. The results in discussion section shows that students incorporated most peer comments on lexicon, grammar and mechanics. The number of peer comments incorporated on organization and ideas was relatively small, but still, more than half of peer comments on these two dimensions were incorporated. All these prove that in one way or another peer feedback does help college students to improve their writings.

Research question 2: What are the students' attitudes towards peer feedback?

Generally, students hold a positive viewpoint towards peer feedback. Their attitudes towards peer feedback are clearly reflected in the questionnaires. Most of the students trust their classmates' ability to provide qualified feedback. They consider this as a chance to exchange ideas with their peers. Moreover, peer feedback, compared to teacher feedback, creates a relaxing atmosphere which lessens their stress and encourages them to involve more in English writing. Their responses in the interview also reflect their affirmation towards peer feedback. In their own words, they surely learn from each other through peer feedback activity because everyone may boast lore that the other might not know of. In addition, their awareness of their own weaknesses is raised by reading their classmates' compositions. Students admit that they are not able to spot their own weaknesses in their own compositions, whereas reading other's writing helps them to realize their own problems. This is achieved not only through getting comments from their peers but also by providing feedback to peers as well.

Thus, the following conclusions could be drawn:

1) Improvement in writing could be achieved through peer feedback. Through reviewing peers' writing and giving feedback to peers, students enhance their writing ability. And also within this process critical thinking is encouraged, confidence secured, and interest stimulated.

2) With high incorporation rate as shown in the above analysis, peer feedback enjoys positive attitude among students. Most students prefer peer comment due to the act of reading, reviewing and receiving feedback which deepens their thought, improves their writing ability and increases their awareness of the readers.

Because all the subjects coming from the same university and the number is very small, the results and conclusion may lack of generality and need further justification.

\section{References}

Berger, V. (1990). The effects of peer and self-feedback. California Teachers of English to Speakers of Other Languages Journal, (3).

Carson, J. G., \& Nelson, G. L. (1996). Chinese students' perceptions of ESL peer response group interaction. Journal of Second Language Writing, 5, 1-19. https://doi.org/10.1016/S1060-3743(96)90012-0

Connors, R. J., \& Andrea A. L. (1993). Teachers' rhetorical comments on student papers. CCC, 44(2), 200-223. https://doi.org/10.2307/358839

Dana, E., \& Hedgcock, J. S. (2005). Teaching ESL Composition: Purpose, Process and Practice (2nd ed.). 
Mahwah, NJ: Lawrence Erlbaum Associates, Publishers.

Ellis, R. (2009) A typology of written corrective feedback types. ELT Journal, 63(2), 97-107. https://doi.org/10.1093/elt/ccn023

Ferris, D. R. (1997). The influence of teacher commentary on student revision. TESOL Quarterly, 31(2), 315-339. https://doi.org/10.2307/3588049

Ferris, D. R., \& Roberts, B. (2001). Error feedback in L2 writing classes: How explicit does it need to be? Journal of Second Language Writing, 10, 161-184. https://doi.org/10.1016/S1060-3743(01)00039-X

Hedgecock, J., \& Lefkowitz, N. (1992). Collaborative oral/aural revision in foreign language writing instruction. Journal of Second Language Writing, 1(2), 255-276. https://doi.org/10.1016/1060-3743(92)90006-B

Hyland, F. (1998). The impact of teacher written feedback on individual writer. Journal of Second Language Writing, 7, 255-286. https://doi.org/10.1016/S1060-3743(98)90017-0

Hyland, F., \& Hyland, K. (2001). Sugaring the pill praise and criticism in written feedback. Journal of Second Language Writing, 10, 185-212. https://doi.org/10.1016/S1060-3743(01)00038-8

Jacobs, G. M., Curtis, A., Braine, G., \& Huang, S. Y. (1998). Feedback on student writing: Taking a middle path. Journal of Second Language Writing, 7, 307-317. https://doi.org/10.1016/S1060-3743(98)90019-4

Keh, C. (1990). Feedback in the writing process: A model and methods for implementation. ELT Journal, 4, 294-394. https://doi.org/10.1093/elt/44.4.294

Leki, I. (1991). The preference of ESL students for error correction in college-level writing classes. Foreign Language Annals, 24, 203-218. https://doi.org/10.1111/j.1944-9720.1991.tb00464.x

Lin, Yi-Chia A. (2009). An Examination of Teacher Feedback, Face-to-face Peer feedback, and Google Documents Peer Feedback in Taiwanese EFL College Students' Writing. Unpublished doctoral dissertation, Alliant International University.

Liu, J., \& Hansen, J. G. (2002). Peer Response in Second Language Writing Classrooms. Ann Arbor: The University of Michigan Press. https://doi.org/10.3998/mpub.8952

Mangelsdorf, K., \& Schlumberger, A. (1992). ESL student response stances in a peer-review task. Journal of Second Language Writing, 1(3), 235-254. https://doi.org/10.1016/1060-3743(92)90005-A

Mei, T., \& Yuan, Q. (2010). A case study of peer feedback in the Chinese EFL writing classroom. Chinese Linguistics, (4).

Mendonça, C. O., \& Johnson, K. E. (1994). Peer review negotiations: Revision activities in ESL writing instruction. TESOL Quarterly, 28(4), 745-769. https://doi.org/10.2307/3587558

Miao, Y., \& Badger, R. (2006). A comparative study of peer and teacher feedback in a Chinese EFL writing class. Journal of Second Language Writing, (3).

Mittan, R. (1989). The peer review process: Harnessing students' communicative power. In D. M. Johnson, \& D. H. Roen (Eds.), Richness in Writing: Empowering ESL Students (pp. 207-219). New York: Longman.

Stanley, J. (1992). Coaching student writers to be effective peer evaluators. Journal of Second Language Writing, 1(3), 217-233. https://doi.org/10.1016/1060-3743(92)90004-9

Vygotsky, L. S. (1978). Mind in Society. Cambridge, MA: Harvard University Press.

Zamel, V. (1982). Writing: The process of discovering meaning. TESOL Quarterly, 16(2), 195-209. https://doi.org/10.2307/3586792

Zhang, S. (1995). Reexamining the affective advantage of peer feedback in the ESL writing class. Journal of Second Language Writing, 4, 209-222. https://doi.org/10.1016/1060-3743(95)90010-1

\section{Copyrights}

Copyright for this article is retained by the author(s), with first publication rights granted to the journal.

This is an open-access article distributed under the terms and conditions of the Creative Commons Attribution license (http://creativecommons.org/licenses/by/4.0/). 